\title{
Comparison of open repair and modified percutaneous repair techniques for the treatment of acute Achilles tendon ruptures
}

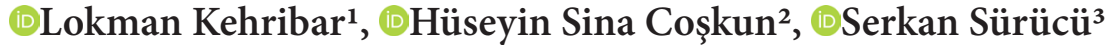 \\ ${ }^{1}$ Samsun University, Faculty of Medicine, Department of Orthopedics and Traumatology, Samsun, Turkey \\ ${ }^{2}$ Ondokuz Mayıs University Faculty of Medicine, Department of Orthopedics and Traumatology, Samsun, Turkey \\ ${ }^{3}$ University of Missouri Kansas City, Department of Orthopaedic Surgery, USA
}

Cite this article as: Kehribar L, Coşkun HS, Sürücü S. Comparison of open repair and modified percutaneous repair techniques for the treatment of acute Achilles tendon ruptures. J Health Sci Med 2022; 5(1): 282-286.

\begin{abstract}
Background: This study compared acute Achilles tendon repairs' functional and clinical outcomes with two different surgical techniques; modified percutaneous and open repair.

Material and Method: This retrospective study analyzed 57 patients with an acute Achilles tendon rupture (AATR) who underwent modified percutaneous and open repair. 46 patients who met the eligibility criteria were enrolled and divided into two groups based on the surgical technique. 23 patients from Group 1 were treated using modified percutaneous repair under local anesthesia, and 23 patients from Group 2 were treated with an open repair under regional anesthesia. Postoperatively, patients were evaluated using American Orthopedic Foot and Ankle Society (AOFAS) Hindfoot Questionnaire score at final follow-up. The other outcomes included return to work, return to sports activities, capacity to complete single heel rise, leg circumference, estimated limb symmetry indices, Achilles tendon resting angle (ATRA), complications, and timing of index surgery.

Results: At the time of surgery, the mean age of the patients was 35.97 .5 years (range, 25-47 years). The average follow-up was $34.8 \pm 6.5$ months (24-52 months). The mean age, gender, body mass index (BMI), rupture level, duration from injury to surgery, and mean follow-up time were similar in both groups. At a minimum 2-year follow-up, good pain relief was achieved for all

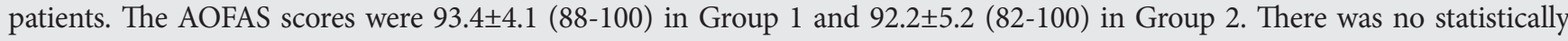
significant difference between groups concerning the Achilles tendon resting angle (ATRA), calf circumference, single-leg heel rise, return to work, and return to sports activities. However, the percutaneous repair procedure had a shorter surgical time than the open repair technique $(\mathrm{p}<0.05)$.

Conclusion: Modified percutaneous and open repair techniques provide similar clinical and functional outcomes, but the percutaneous repair technique showed faster surgical time than open procedures. Furthermore, the percutaneous technique may be more practical than the open technique, which may be performed under local anesthesia.
\end{abstract}

Keywords: Achilles tendon, rupture, repair, percutaneous

\section{INTRODUCTION}

Despite advancements in treatment and rehabilitation, the ideal management of acute Achilles tendon rupture (AATR) continues to be debated (1). Several treatment options have been recommended, including immediate immobilization, open repair, percutaneous repair, and functional rehabilitation (2-4). Conventionally, the open repair was favored secondary to its lower re-rupture rates, however in more recent years, and there has been a progressive shift away from surgical intervention to reduce wound complications $(5,6)$. On the other hand, conservative options have been shown to carry an increased rate of re-rupture and tendon lengthening and other long-term complications $(7,8)$. Percutaneous repair has been criticized for healing in a lengthened tendon position and exposing the sural nerve to a significant risk of injury (9-11). Currently, there is no decision on the best method to be used, with advantages and disadvantages for all options.

Recently, meta-analyses showed that the percutaneous techniques promoted faster surgical time, lower rate of wound complications, and a similar re-rupture risk compared to an open repair $(6,12)$. Many surgeons advocate for open repair despite improved percutaneous techniques because of reliable anatomical tendon repair with direct visualization and lower re-rupture risk $(13,14)$. There is still disagreement over which method is more effective: open or percutaneous. 
This study aimed to assess the functional and clinical outcomes of modified percutaneous and open Achilles tendon repairs. We hypothesized that a modified percutaneous technique with a sliding knot using absorbable sutures would have clinical outcomes comparable to an open repair technique.

\section{MATERIAL AND METHOD}

The study was carried out with the permission of Ondokuz Mayıs University Clinical Researchs Ethics Committee (Date: 23.09.2021, Decision No: 2021/424). All procedures were carried out in accordance with the ethical rules and the principles of the Declaration of Helsinki.

This retrospective analysis comprised 57 individuals who had an acute Achilles tendon rupture (AATR) and underwent modified percutaneous and open repair. All of the ruptures were occurred during a sporting activity, mainly while running or playing football. The inclusion criteria were as follows: (1) patients with an AATR time from injury of less than ten days; (2) age range of 1860 years; (3) no history of ankle pathology; and (4) no significant comorbidities. Eleven patients were excluded from the study because of rheumatoid arthritis $(n=1)$, immunodeficiency $(\mathrm{n}=1)$, less than 24 months follow-up $(n=5)$, and chronic rupture $(n=4) .46$ patients who met the criteria were enrolled and divided into two groups based on the surgical technique. Group 1 comprised 23 patients who were treated with a modified percutaneous repair. Group 2 was comprised of 23 patients who were treated with an open repair.

\section{Physical and Clinical Assessment}

All patients underwent a full physical examination preoperatively, including an ankle range of motion test, the Thompson test, and a gap palpation test. Patients were evaluated using the American Orthopedic Foot and Ankle Society (AOFAS) Hindfoot Questionnaire score at the final follow-up. Additionally, the ability to perform single heel rises, leg circumference, calculated limb symmetry indexes, Achilles tendon resting angle (ATRA), complications, and timing of surgery were evaluated.

\section{Surgical Technique}

All patients were positioned prone without the use of a tourniquet. The study's senior author carried out all procedures.

In Group 1, modified percutaneous repair with a sliding knot using absorbable suture was performed under local anesthesia. Tendon gaps and stumps were identified, and three pairs of stab incisions were made at each ruptured tendon end. Tendon ends were sutured according to Bunnell type repair, and the suture ends were pulled to tighten at the level of the middle medial stab incision. A non-locking loop was created using a sliding knot by pulling the post strand. The length of the repaired tendon was estimated by measuring the Achilles' resting angle of the contralateral foot. The palpable gap disappeared, and finally, the incisions were closed with absorbable sutures (Figure 1).

In group 2, the open repair was performed under spinal anesthesia. A posteromedial approach was used to access the Achilles tendon. Ruptured tendon fascicles were adapted and sutured with modified Kessler type repair using absorbable suture (No:1 PDS). Further continuous sutures were applied to encircle the fascicles. The paratenon and fascia were then thoroughly repaired. Finally, the wound was closed with an absorbable suture.

\section{Postoperative Rehabilitation}

Each group followed a similar postoperative rehabilitation protocol. A short leg cast was applied with the ankle for two weeks in $20^{\circ}$ of equinus. The cast was changed after soft tissue healing with a second cast set at a $10^{\circ}$ plantarflexion angle for two weeks. During this period, muscle strengthening exercises were recommended with partial weight-bearing. After four weeks, patients were instructed to walk with weight-bearing and perform isokinetic and isometric strengthening exercises.

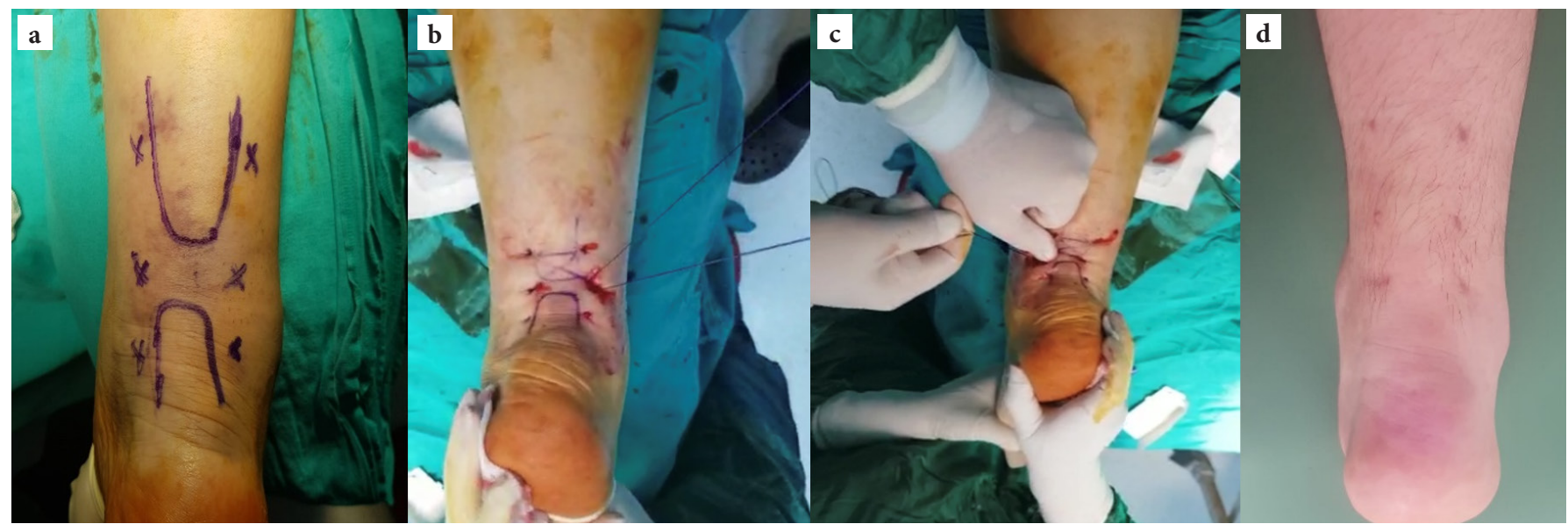

Figure. a) Marking the skin for the suture pass points. Note the gap where the rupture occurred $\mathbf{b}$ ) and c) Thightening the suture on the medial side of the foot and using it as a gliding suture. d) Completely healed wound after three months postoperatively. 


\section{Statistical Analysis}

Power analysis has been done for the study. The statistical analysis was performed using Statistical Package for Social Sciences (SPSS) Version 21.0 statistical analysis software. The Shapiro-Wilk test defined normal distribution. The postoperative comparisons were performed using the Student t-test as quantitative data. The quantitative data were shown as the mean \pm standard deviation. The sample size was determined using a power analysis, which found that at least 20 patients were required for each group to achieve a minimum power of $80 \%$ with a $5 \%$ alpha error.

\section{RESULTS}

This study enrolled 46 patients (33 males and 13 females). At the time of surgery, the mean age of the patients was $35.9 \pm 7.5$ years (range, $25-47$ years). The average followup was 34.8 \pm 6.5 months (24-52 months). The mean age, gender, body mass index (BMI), rupture level, duration from injury to surgery, and mean follow-up time were similar in both groups. Detailed comparative demographics in both groups are shown in Table 1.

\section{Table 1. Patient demographics}

\begin{tabular}{|c|c|c|c|}
\hline & \multicolumn{2}{|c|}{ Mean \pm SD (Range) } & \multirow{2}{*}{$\begin{array}{c}P \\
\text { value }\end{array}$} \\
\hline & Group $1(n=23)$ & Group $2(n=23)$ & \\
\hline Age & $\begin{array}{c}37.5 \pm 6.1 \\
(28-47)\end{array}$ & $\begin{array}{c}34.6 \pm 5.5 \\
(25-42)\end{array}$ & 0.625 \\
\hline $\operatorname{Sex}(M / F)$ & $17 / 6$ & $16 / 7$ & 0.562 \\
\hline $\begin{array}{l}\mathrm{BMI} \\
(\mathrm{kg} / \mathrm{m} 2)\end{array}$ & $\begin{array}{l}26.6 \pm 3.4 \\
(21-32)\end{array}$ & $\begin{array}{c}25.3 \pm 4.5 \\
(22-34)\end{array}$ & 0.821 \\
\hline Side (R/L) & $12 / 14$ & $12 / 11$ & 0.235 \\
\hline $\begin{array}{l}\text { Level of rupture } \\
(\mathrm{cm})\end{array}$ & $\begin{array}{c}5.6 \pm 1.2 \\
(4.5-6.5)\end{array}$ & $\begin{array}{l}5.1 \pm 2.3 \\
(4-6.5)\end{array}$ & 0.461 \\
\hline $\begin{array}{l}\text { Time from injury } \\
\text { to surgery (days) }\end{array}$ & $\begin{array}{c}3.1 \pm 1.7 \\
(1-8)\end{array}$ & $\begin{array}{c}2.5 \pm 2.1 \\
(0-9)\end{array}$ & 0.523 \\
\hline $\begin{array}{l}\text { Follow-up } \\
\text { (months) }\end{array}$ & $\begin{array}{c}33.2 \pm 7.2 \\
(24-46)\end{array}$ & $\begin{array}{c}35.1 \pm 7.8 \\
(24-52)\end{array}$ & 0.341 \\
\hline
\end{tabular}

At a minimum two-year follow-up, all patients achieved significant pain relief. The functional outcomes were similar in both groups. The AOFAS scores were 93.4 \pm 4.1 (88-100) in Group 1 and 92.2 55.2 (82-100) in Group 2. There was no statistically significant difference between groups concerning the Achilles tendon resting angle (ATRA), calf circumference, single-leg heel raise, return to work, return to sports. The indexes of limb symmetry for an ATRA, calf circumference, and singleleg heel rise were not significantly different. However, the percutaneous repair procedure was found to have a much shorter surgical duration than the open repair technique $(\mathrm{p}<0.05)$. Table 2 summarizes the statistical comparisons between the two groups.
Table 2. The comparison of clinical and functional outcomes of groups

\begin{tabular}{|c|c|c|c|}
\hline & \multicolumn{2}{|c|}{ Mean \pm SD (Range) } & \multirow{2}{*}{$\begin{array}{c}P \\
\text { value }\end{array}$} \\
\hline & $\underset{(n=23)}{\text { Group } 1}$ & $\underset{(n=23)}{\text { Group } 2}$ & \\
\hline AOFAS score & $\begin{array}{l}93.4 \pm 4.1 \\
(88-100)\end{array}$ & $\begin{array}{l}92.2 \pm 5.2 \\
(82-100)\end{array}$ & 0.118 \\
\hline ATRA (degree) & $\begin{array}{l}55.4 \pm 6.2 \\
(45-74)\end{array}$ & $\begin{array}{c}54.1 \pm 5.3 \\
(42-76)\end{array}$ & 0.234 \\
\hline ATRA LS index (\%) & $\begin{array}{l}102.5 \pm 6.8 \\
(95-130)\end{array}$ & $\begin{array}{l}101.3 \pm 5.4 \\
(90-135)\end{array}$ & 0.315 \\
\hline $\begin{array}{l}\text { Calf circumference } \\
(\mathrm{cm})\end{array}$ & $\begin{array}{l}38.4 \pm 7.1 \\
(28-49)\end{array}$ & $\begin{array}{l}34.6 \pm 6.4 \\
(24-43)\end{array}$ & 0.254 \\
\hline $\begin{array}{l}\text { Calf circumference } \\
\text { LS index (\%) }\end{array}$ & $\begin{array}{l}95.4 \pm 5.6 \\
(88-103)\end{array}$ & $\begin{array}{l}92.6 \pm 5.2 \\
(85-104)\end{array}$ & 0.556 \\
\hline $\begin{array}{l}\text { Single leg heel raise } \\
\text { (count) }\end{array}$ & $\begin{array}{l}39.5 \pm 8.3 \\
(27-96)\end{array}$ & $\begin{array}{c}38.2 \pm 7.4 \\
(26-95)\end{array}$ & 0.343 \\
\hline $\begin{array}{l}\text { Single leg heel raise } \\
\text { LS index }(\%)\end{array}$ & $\begin{array}{l}84.6 \pm 10.1 \\
(52-115)\end{array}$ & $\begin{array}{l}82.1 \pm 8.6 \\
(50-110)\end{array}$ & 0.253 \\
\hline $\begin{array}{l}\text { Return to work } \\
\text { (day) }\end{array}$ & $\begin{array}{c}41.3 \pm 6.7 \\
(32-58)\end{array}$ & $\begin{array}{l}46.8 \pm 5.6 \\
(36-60)\end{array}$ & 0.152 \\
\hline $\begin{array}{l}\text { Return to sports } \\
\text { (month) }\end{array}$ & $\begin{array}{l}4.5 \pm 1.2 \\
(3-6)\end{array}$ & $\begin{array}{l}4.8 \pm 1.5 \\
(3-8)\end{array}$ & 0.142 \\
\hline $\begin{array}{l}\text { Operation duration } \\
\text { (min) }\end{array}$ & $\begin{array}{l}14.4 \pm 3.2 \\
(10-23)\end{array}$ & $\begin{array}{l}32.6 \pm 6.1 \\
(25-44)\end{array}$ & 0.001 \\
\hline \multicolumn{4}{|c|}{$\begin{array}{l}\text { Group 1: Modified percutaneous repair; Group 2: Open repair; AOFAS: American } \\
\text { Orthopaedic Foot Ankle Society Rating Score; ATRA: Achilles tendon resting angle; } \\
\text { LS Index: Limb symmetry index= affected limb side/healthy limb side }{ }^{*} 100 \% \text {; SD: } \\
\text { standard deviation; }{ }^{*} p<0.05 \text { statistically significant }\end{array}$} \\
\hline
\end{tabular}

Temporarily sural nerve damage was found in 2 patients in Group 1. Two patients had developed superficial wound infections in Group 2.

\section{DISCUSSION}

The percutaneous technique was first described in 1977 by $\mathrm{Ma}$ and Griffith (15). Since then, this procedure has gained wide acceptance as a treatment option with satisfactory outcomes to minimize the wound complications related to the open procedure. However, this technique was criticized for re-ruptures based on inadequate suturing due to no visualization of the tendon $(3,8)$. Also, this approach was more prone to sural nerve injury and tendon elongation. However, surgical techniques have continued to evolve. Initially, a sural nerve palsy rate of up to $60 \%$ has been reported, whereas the most recent studies reported the occurrence rate was 5.5\% (16). Nowadays, studies reveal the anatomy more detailed than before, so thanks to this, we can safely perform the percutaneous repair (17). In our study, the temporary sural nerve damage was found in two patients in the percutaneous group.

Although percutaneous AATR surgery has gained favor, some surgeons advocate for open repair due to biomechanical strength issues (18). Because of the direct visualization of the ruptured tendon, the authors believe that the incidence rate of re-rupture may decrease. However, previously conducted meta-analyses suggested 
no significant difference in the re-rupture rate between the percutaneously and open techniques $(12,19)$. On the other hand, wound healing problems with deep infection continue to be a concern. The deep infection rate has been reported to reach up to $20 \%$ (20). In our study, two patients had developed superficial wound infections in the open repair group.

In their meta-analysis, Yang et al. (12) suggested that percutaneous repair is superior to open repair for treating AATR. They reported that the percutaneous technique has several advantages, including operation duration, lower rate of deep infection, and higher AOFAS score. Similarly, Makulavicius et al. (3) reported that both percutaneous and open repair procedures were effective, safe, and resulted in a high level of patient satisfaction. Furthermore, they showed that the percutaneous technique was significantly faster than the open technique. Likewise, in our study, the surgical duration of the percutaneous repair was found significantly lower than an open repair technique. Also, the percutaneous repair was performed under local anesthesia in all patients. However, the open repair was required regional anesthesia.

Achilles tendon elongation after surgery and adjustment of the tendon length are the major concerns for surgeons in percutaneous techniques $(11,21)$. Several studies showed that the plantar flexion strength and single-leg heel raise endurance decreased after Achilles tendon elongation $(10,22)$. These findings reiterated skepticism about the dilemma for open or percutaneous repair techniques. Clanton et al. (13) found that the percutaneous repair techniques demonstrated significantly early elongation than open repair techniques. They reported that the primary elongation mechanism resulted from cutout at the suture-tendon interface and knot slipping or stretching. Our study suggested the modified percutaneous technique with a sliding knot to reduce the knot-related complications causing the tendon elongation. The superiority of the presented modified method consists of non-locking and sliding knot mechanisms. It maintains the restoration of the original tendon length and provides good tendon healing without elongation.

Furthermore, it allows the repair of the ruptured tendon in similar tension with the contralateral side. Intraoperatively, tightness of tendon repair was quantified using the contralateral ATRA. At the final follow-up, there was no statistically significant difference between open and percutaneous techniques concerning the ATRA limb symmetry index.

The study's main significant finding was that open and modified percutaneous repair procedures are equally effective, yielding "excellent and good" clinical outcomes following AATR. Furthermore, compared to open repair, the percutaneous technique had a much shorter surgery duration. The percutaneous Achilles tendon repair has a higher risk of sural nerve damage but a lesser risk of wound complications/infection than open repair.

Our study noted that there were no significant difference in terms of returning to work and sport. We expected an earlier return in the percutaneous group. Still, we concluded that return to work and sporting activity is a subjective factor depending on the patient's pre-injury activity level and many other factors. This part needs to be clarified in light of future studies. It is critical to resume previous activities. Both time and pre-injury level recovery need to be considered. Although the rate of sports discontinuation is up to $8.6 \%$ following percutaneous repair, $78 \%$ of athletes returned to their previous activity level (23).

The study had several limitations. The major limitation of this study was its retrospective design and small sample size. In addition, muscle strength and endurance were not evaluated with a specialized device. Further researches are needed to make precise conclusions on this subject.

\section{CONCLUSION}

Modified percutaneous and open repair techniques provide similar clinical and functional outcomes. But, the percutaneous repair technique showed faster surgical duration than the open technique. Furthermore, the percutaneous technique may be practical because it may be performed under local anesthesia.

\section{ETHICAL DECLARATIONS}

Ethical Committee Approval: The study was carried out with the permission of Ondokuz Mayis University Clinical Researchs Ethics Committee (Date: 23.09.2021, Decision No: 2021/424).

Informed Consent: Because the study was designed retrospectively, no written informed consent form was obtained from patients.

Conflict of Interest Statement: The authors declare no conflicts of interest.

Financial Disclosure: The authors declared that this study had received no financial support.

Author Contributions: All of the authors declare that they have all participated in the paper's design, execution, and analysis and that they have approved the final version.

\section{REFERENCES}

1. Meulenkamp B, Woolnough T, Cheng W, et al. What is the best evidence to guide management of acute Achilles tendon ruptures? a systematic review and network meta-analysis of randomized controlled trials. Clin Orthop Relat Res 2021; 479: 2119-31. 
2. Deng S, Sun Z, Zhang C, Chen G, Li J. Surgical treatment versus conservative management for acute Achilles tendon rupture: a systematic review and meta-analysis of randomized controlled trials. J Foot Ankle Surg 2017; 56: 1236-43.

3. Makulavicius A, Mazarevicius G, Klinga M, et al. Outcomes of open "crown" type v. percutaneous Bunnell type repair of acute Achilles tendon ruptures. Randomized control study. Foot Ankle Surg 2020; 26: 580-4.

4. Reda Y, Farouk A, Abdelmonem I, El Shazly OA. Surgical versus non-surgical treatment for acute Achilles' tendon rupture. A systematic review of literature and meta-analysis. Foot Ankle Surg 2020; 26: 280-8.

5. Lerch TD, Schwinghammer A, Schmaranzer F, et al. Return to sport and patient satisfaction at 5-year follow-up after nonoperative treatment for acute Achilles tendon rupture. Foot Ankle Int 2020; 41: 784-92.

6. Shi F, Wu S, Cai W, Zhao Y. Multiple comparisons of the efficacy and safety for six treatments in acute Achilles tendon rupture patients: A systematic review and network meta-analysis. Foot Ankle Surg 2021; 27: 468-79.

7. Heikkinen J, Lantto I, Piilonen J, et al. Tendon length, calf muscle atrophy, and strength deficit after acute Achilles tendon rupture: long-term follow-up of patients in a previous study. J Bone Joint Surg Am 2017; 99: 1509-15.

8. Stavenuiter XJR, Lubberts B, Prince RM, 3rd, Johnson AH, DiGiovanni CW, Guss D. Postoperative Complications Following Repair of Acute Achilles Tendon Rupture. Foot Ankle Int 2019; 40: 679-86.

9. Carmont MR, Zellers JA, Brorsson A, Nilsson-Helander K, Karlsson J, Gravare Silbernagel K. Age and tightness of repair are predictors of heel-rise height after Achilles tendon rupture. Orthop J Sports Med 2020; 8: 2325967120909556.

10. Schaarup SO, Wetke E, Konradsen LAG, Calder JDF. Loss of the knee-ankle coupling and unrecognized elongation in Achilles tendon rupture: effects of differential elongation of the gastrocnemius tendon. Knee Surg Sports Traumatol Arthrosc 2021; 29: 2535-44.

11. Yassin M, Myatt R, Thomas W, Gupta V, Hoque T, Mahadevan D. Does size of tendon gap affect patient-reported outcome following Achilles tendon rupture treated with functional rehabilitation? Bone Joint J 2020; 102: 1535-41.

12. Yang B, Liu Y, Kan S, et al. Outcomes and complications of percutaneous versus open repair of acute Achilles tendon rupture: A meta-analysis. Int J Surg 2017; 40: 178-86.

13. Clanton TO, Haytmanek CT, Williams BT, et al. A biomechanical comparison of an open repair and 3 minimally invasive percutaneous Achilles tendon repair techniques during a simulated, progressive rehabilitation protocol. Am J Sports Med 2015; 43: 1957-64.

14. Diniz P, Pacheco J, Fernandes RM, Pereira H, Castelo Ferreira F, Kerkhoffs G. Modified triple Kessler with least risk of elongation among Achilles tendon repair techniques: a systematic review and network meta-analysis of human cadaveric studies. Knee Surg Sports Traumatol Arthrosc 2021.

15. Ma GW, Griffith TG. Percutaneous repair of acute closed ruptured Achilles tendon: a new technique. Clin Orthop Relat Res 1977: 247-55.

16. Cretnik A, Kosanovic M, Kosir R. Long-Term Results With the Use of Modified Percutaneous Repair of the Ruptured Achilles Tendon Under Local Anaesthesia (15-Year Analysis With 270 Cases). J Foot Ankle Surg 2019; 58: 828-36.

17. McGee R, Watson T, Eudy A, et al. Anatomic relationship of the sural nerve when performing Achilles tendon repair using the percutaneous Achilles repair system, a cadaveric study. Foot Ankle Surg 2021; 27: 427-31.

18. Wenning M, Mauch M, Heitner A, Streicher P, Ritzmann R, Paul J. Midterm functional performance following open surgical repair of acute Achilles tendon rupture. Arch Orthop Trauma Surg 2021.
19. Maempel JF, Clement ND, Wickramasinghe NR, Duckworth AD, Keating JF. Operative repair of acute Achilles tendon rupture does not give superior patient-reported outcomes to nonoperative management. Bone Joint J 2020; 102: 933-40.

20. Gatz M, Driessen A, Eschweiler J, Tingart M, Migliorini F. Open versus minimally-invasive surgery for Achilles tendon rupture: a meta-analysis study. Arch Orthop Trauma Surg 2021; 141: 383 401.

21. Agres AN, Arampatzis A, Gehlen T, Manegold S, Duda GN. Muscle fascicles exhibit limited passive elongation throughout the rehabilitation of Achilles tendon rupture after percutaneous repair. Front Physiol 2020; 11: 746

22. Hurmeydan OM, Demirel M, Valiyev N, Sahinkaya T, Kilicoglu OI. Relationship of postoperative Achilles tendon elongation with plantarflexion strength following surgical repair. Foot Ankle Int 2020; 41: 140-6.

23. Ververidis AN, Touzopoulos P, Drosos GI, Tilkeridis KE, Kazakos KI. Percutaneous repair of the Achilles tendon rupture in athletic population. Journal of orthopaedics 2016; 13: 57-61. 